\title{
Contribution of cod liver oil supplements to intake and associations with biomarkers of fatty acids in the European Prospective Investigation into Cancer (EPIC-Norfolk) Study
}

\author{
M. A. H. Lentjes ${ }^{1}$, A. Bhaniani ${ }^{1}$, A. A. Mulligan ${ }^{1}$, A. A. Welch ${ }^{2}$ and K. T. Khaw ${ }^{3}$ \\ ${ }^{1}$ Department of Public Health and Primary Care, University of Cambridge, Worts Causeway, Cambridge CB1 8RN, \\ ${ }^{2}$ Norwich Medical School, University of East Anglia, Norwich and ${ }^{3}$ Clinical Gerontology, University of Cambridge, \\ Cambridge
}

Supplements contribute to nutrient intakes and are used by $34 \%$ of men and $46 \%$ of women participating in the European Prospective Investigation into Cancer in Norfolk (EPIC-Norfolk) ${ }^{(1)}$. As cod liver oil (CLO) supplements are the most frequently consumed group, this cross-sectional study aimed to assess their contribution to nutrient intakes, (EPA, DHA and vitamins A and D) and to determine whether inclusion of supplement data improved the association between nutrient intake and corresponding biomarkers, i.e. blood plasma concentrations of EPA and DHA.

EPIC-Norfolk is a prospective cohort study investigating determinants of chronic diseases in free-living individuals, aged 40-79 years, recruited from the general population between 1993 and $1998^{(2)}$. Participants filled in a 7-d diet diary ${ }^{(3,4)}$, in which they also recorded their dietary supplement use ${ }^{(1)}$.

Chi-square tests indicated that supplement use increased with age in men only $\left(P_{\text {trend }}<0.001\right)$ and that the proportion of CLO containing supplements increased with age for men and women $\left(P_{\text {trend }}<0.001\right)$. Median nutrient intake increased after inclusion of supplement sources (Table); and resulted in a shift in the quintile distribution for $18-26 \%$ of the participants for fatty acids and for $36-51 \%$ of the participants for vitamins $\mathrm{A}$ and $\mathrm{D}$.

\begin{tabular}{|c|c|c|c|c|c|c|c|c|}
\hline & \multicolumn{4}{|c|}{$\operatorname{Men}(n 8706)$} & \multicolumn{4}{|c|}{ Women $(n$ 9912) } \\
\hline & \multicolumn{2}{|c|}{ Food only } & \multicolumn{2}{|c|}{ Food + suppl intake } & \multicolumn{2}{|c|}{ Food only } & \multicolumn{2}{|c|}{ Food + suppl intake } \\
\hline & Median & IQR & Median & $\mathrm{IQR}$ & Median & IQR & Median & $\mathrm{IQR}$ \\
\hline EPA (g/d) & 0.06 & $0.03-0.15$ & 0.07 & $0.03-0.18$ & 0.05 & $0.02-0.13$ & 0.06 & $0.03-0.15$ \\
\hline DHA $(g / d)$ & 0.08 & $0.04-0.22$ & 0.09 & $0.04-0.26$ & 0.07 & $0.03-0.20$ & 0.08 & $0.04-0.23$ \\
\hline Vitamin A (mcg/d) & 394 & $266-607$ & 516 & $311-1073$ & 305 & $210-459$ & 444 & $254-1040$ \\
\hline Vitamin D (mcg/d) & 3.19 & $2.09-4.79$ & 3.96 & $2.41-6.35$ & 2.52 & $1.67-3.79$ & 3.55 & $2.03-5.83$ \\
\hline
\end{tabular}

Participants were divided into three groups: non-supplement users (NSU $\diamond$ ), supplement users not using CLO (SU-CLOロ) and SU using CLO (SU + CLO $\mathbf{\Delta}$ ). In participants with blood plasma concentrations ( $n 3371$ men, $n 3174$ women), ANOVA showed higher plasma levels for EPA (40\%) and DHA (19\%) for the SU + CLO compared with NSU, after correcting for quintiles of food sources of respective fatty acids $(P<0.001$, Figure).
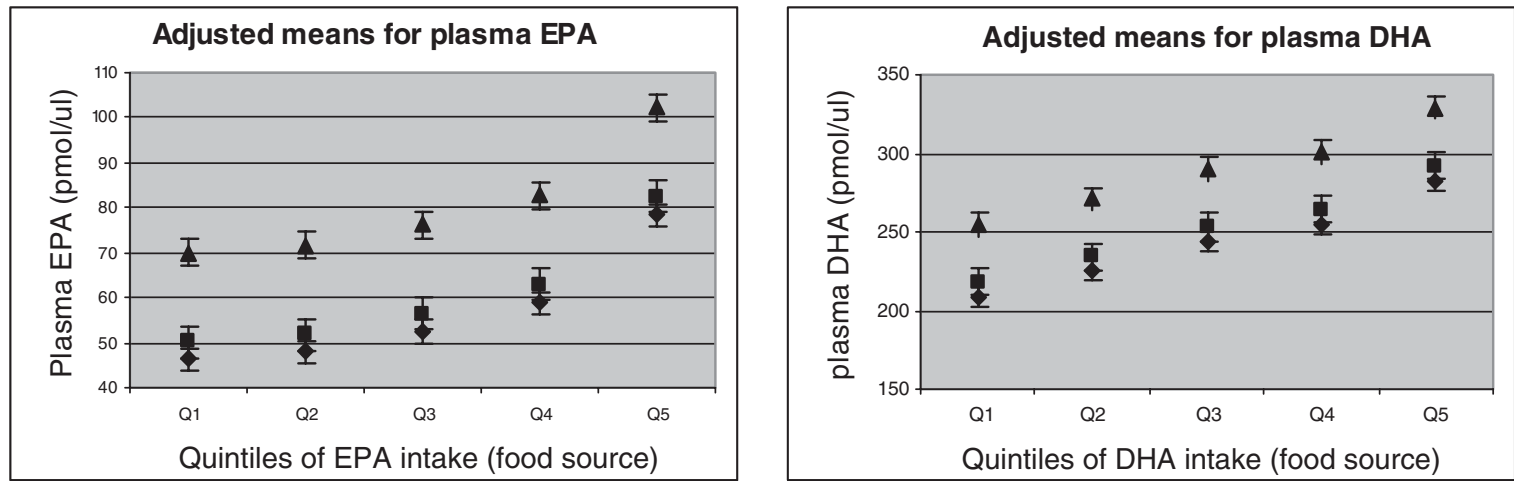

Consumption of supplements contributed to intakes of EPA, DHA and vitamins A and D and had substantial effects on classification of individuals within this population distribution. The association between intake and plasma fatty acids were similar for SU and NSU, but the absolute values for SU were higher, demonstrating the contribution supplements make. Omitting data for intakes from supplements could be a source of error in diet and disease associations.

1. Lentjes MA, Bhaniani A, Mulligan AA et al. (2011) Public Health Nutr 17, 1-13.

2. Day N, Oakes S, Luben R et al. (1999) Br J Cancer 80, 95-103.

3. Welch AA, McTaggart A, Mulligan AA et al. (2001) Public Health Nutr 4, 1253-1265.

4. Bingham SA, Welch AA, McTaggart A et al. (2001) Public Health Nutr 4, 847-858. 